\title{
Obesity: A review of pathogenesis and management strategies
}

\author{
Brinderjit Kaila MD FRCPC, Maitreyi Raman MD FRCPC
}

B Kaila, M Raman. Obesity: A review of pathogenesis and management strategies. Can J Gastroenterol 2008;22(1):6168.

The prevalence of obesity in the developed world is increasing. Approximately $23 \%$ of adult Canadians (5.5 million people) are obese. Obesity is associated with an increased risk of developing several comorbid diseases, ranging from cardiovascular diseases to cholelithiasis and nonalcoholic fatty liver disease. The etiology of obesity is multifactorial, involving a complex interaction among genetics, hormones and the environment. The available evidence and recommendations for nonpharmacological management of obesity, including dietary therapy, physical activity and behavioural therapy, in addition to pharmacotherapy are discussed. A brief discussion on endoscopic and surgical procedures is undertaken. Several antiobesity treatment options are available and may be indicated in appropriate situations. Selecting obesity therapy may be guided by body mass index measurements, comorbid illnesses and patient preference.

Key Words: Management; Obesity; Pathogenesis

$\mathrm{T}$ he prevalence of obesity in the developed world is increasing. Approximately 23\% of adult Canadians (5.5 million people) are obese (defined as a body mass index [BMI] greater than $30 \mathrm{~kg} / \mathrm{m}^{2}$ ) and an additional 36\% are overweight (BMI of $25 \mathrm{~kg} / \mathrm{m}^{2}$ or more) (1), compared with obesity rates of only $14 \%$ in the late 1970 s.

The rise in obesity is likely multifactorial. Although there is certainly a genetic predisposition to obesity (discussed below), several environmental factors are also implicated (2), including excess portion size, dietary macronutrient composition and sedentary lifestyle in the setting of modern-day conveniences.

Obesity-related comorbidities incur major health care costs, with an estimated direct annual cost of $\$ 1,800,000,000$, which is approximately $2.4 \%$ of the total health care expenditure (3). It is associated with an increased risk of several diseases: coronary artery disease, cerebrovascular disease, hypertension, hyperlipidemia, type II diabetes, cholelithiasis, pulmonary embolism, sleep apnea, gynecological abnormalities, osteoarthritis, psychiatric illness and malignancy (breast, endometrial, prostate and colon). Furthermore, it is an independent risk factor for increased mortality (3).

Obesity has major health implications in gastroenterology because it plays a major role in the pathogenesis of nonalcoholic fatty liver disease (NAFLD). NAFLD is the most common cause of abnormal liver tests in North America, with a prevalence of $32 \%$ in obese males and $42 \%$ in obese

\section{Obésité : Pathogenèse et stratégies de prise en charge}

La prévalence de l'obésité dans le monde industrialisé est en hausse. Environ $23 \%$ des Canadiens adultes (5,5 millions de personnes) souffrent d'obésité. L'obésité est associée à un risque accru à l'égard de plusieurs comorbidités, qui vont des maladies cardiovasculaires à la cholélithiase, en passant par la maladie du foie gras non alcoolique. L'étiologie de l'obésité est plurifactorielle et met en cause une interaction complexe entre la génétique, les hormones et l'environnement. Le présent article se propose de faire le point sur les preuves accumulées et sur les recommandations en ce qui a trait à la prise en charge non pharmacologique de l'obésité, y compris par la diétothérapie, l'activité physique et la thérapie comportementale, en plus de la pharmacothérapie, On abordera brièvement les interventions endoscopiques et chirurgicales également. Plusieurs options thérapeutiques anti-obésité sont offertes et peuvent être indiquées selon le cas. Le choix du traitement anti-obésité repose sur l'indice de masse corporelle, la présence de comorbidités et la préférence des patients.

Department of Gastroenterology and Department of Medicine, University of Calgary, Calgary, Alberta

Correspondence: Dr Maitreyi Raman, University of Calgary, 3330 Hospital Drive, Calgary, Alberta T2N 4N1. Telephone 403-220-5767,

fax 403-210-9345, e-mail mkothand@ucalgary.ca

Received for publication June 20, 2007. Accepted June 27, 2007 
Most adults in the United States attempt to lose weight at some point in time (10). Despite these high rates, long-term weight loss maintenance is poor, with $50 \%$ of weight being regained within one year (11). Medically significant benefits can be seen even with small, sustained weight loss (12), emphasizing the need to understand the pathogenesis of obesity, allowing for the development of appropriate therapeutic options.

\section{PATHOGENESIS AND ETIOLOGY}

The etiology of obesity is multifactorial, involving a complex interaction among genetics, hormones and the environment. Though multiple candidate genes have been implicated in the pathogenesis of obesity, these findings are inconsistent $(13,14)$. These genes include the beta-3-adrenergic receptor gene (13), peroxisome-proliferator-activated receptor gamma 2 gene, chromosome 10p, melanocortin-4 receptor gene and other genetic polymorphisms.

Multiple hormones are involved in the regulation and pathophysiology of obesity, including gut-related hormones, adipokines and others. Ghrelin is a circulating peptide hormone derived from the stomach. It is the only known peripherally acting orexigenic hormone and is responsible for stimulating appetite (15). In a double-blind cross-over study, intravenous ghrelin infusion into healthy volunteers led to a $30 \%$ increase in food intake at a buffet, with no change in gastric emptying (16). All other gut-derived hormones serve as anorectic agents that are responsible for limiting food intake to achieve optimal digestion and absorption while avoiding the consequences of overfeeding, such as hyperinsulinemia and insulin resistance. These anorectic gut hormones are discussed below.

Peptide YY (PYY) is found throughout the intestine at progressively higher levels distally, with the highest levels in the colon and rectum. It is secreted by the L cells of the distal small bowel and colon. PYY is released postprandially, and signals to the hypothalamus, resulting in delayed gastric emptying, thus reducing gastric secretion. Administration of PYY before meals results in decreased food consumption (17).

Cholecystokinin (CCK), produced in the gallbladder, pancreas and stomach, and concentrated in the small intestine, is released in response to dietary fat. It regulates gallbladder contraction, pancreatic exocrine secretion, gastric emptying and gut motility. CCK also acts centrally by increasing satiety and decreasing appetite and acts on the satiety signal via subtype CCK-A receptors on the afferent vagal fibres to the brain, causing termination of appetite.

Meal termination is also regulated by postprandial release of oxyntomodulin. This peptide is secreted from the intestinal cells that also secrete PYY. A single infusion of oxyntomodulin suppresses appetite and reduces food intake over a $12 \mathrm{~h}$ period. It is associated with a reduction in fasting ghrelin levels (18).

Glucagon-like peptide-1, which is the 6 to 29 amino acid segment of glucagon, enhances satiety and reduces food intake when administered intravenously to humans (19).

Several hormones, collectively referred to as adipokines, are produced by the adipocytes. The key secretory products are tumour necrosis factor-alpha (TNF- $\alpha$ ), interleukin-6 (IL-6), leptin and adiponectin. The role of TNF- $\alpha$ in obesity has been linked to insulin resistance through the liberation of free fatty acids, reduction in adiponectin synthesis and impairment of insulin signalling. TNF- $\alpha$ also activates nuclear factor-kappa B, leading to a series of inflammatory changes in vascular tissue.

IL-6 is a pleiotropic circulating cytokine resulting in inflammation, impairment of host defenses and tissue injury. It is secreted by many cell types, including immune and endothelial cells, fibroblasts and adipocytes. It acts by inhibiting insulin receptor signal transduction in hepatocytes, increasing circulating free fatty acids from adipose tissue and reducing adiponectin secretion.

Leptin acts as a dominant long-term signal responsible for informing the brain of adipose energy reserves. Leptin is transported across the blood-brain barrier and binds to specific receptors on appetite-modulating neurons and the arcuate nucleus in the hypothalamus, inhibiting appetite. Leptindeficient mice that lack leptin receptors have been shown to be hyperphagic and obese. Furthermore, leptin deficiency reduces energy expenditure (20). True leptin deficiency in humans is rare; however, obese humans are, in part, leptinresistant.

Adiponectin is an adipokine derived from plasma protein. It is insulin sensitizing, anti-inflammatory and antiatherogenic. In contrast to other adipokines, adiponectin messenger RNA (mRNA) levels are reduced in adipose tissue in obese and diabetic individuals (21), and adiponectin levels are restored to normal levels after weight loss (22).

Increased visceral fat results in increased levels of IL-6, TNF- $\alpha$ and C-reactive protein, and reduced levels of adiponectin and interleukin-10, resulting in a proinflammatory milieu that leads to both insulin resistance and endothelial dysfunction, and culminating in the metabolic syndrome, diabetes and atherosclerosis. Visceral adiposity modulates these key regulators of inflammation, and has a proinflammatory potential equivalent to or greater than that of macrophages.

Secondary causes of obesity include drugs, and neuroendocrine diseases (hypothalamic, pituitary, thyroid and adrenal).

\section{TREATMENT}

Weight loss occurs by generating a negative energy balance, which is achieved by consuming fewer calories than energy expended. The evidence and recommendations for nonpharmacological management of obesity, including diet therapy, physical activity and behavioural therapy, as well as pharmacotherapy, and endoscopic and bariatric surgery are discussed in the present review.

\section{Diet therapy}

Although many different types of weight loss diets exist, they all share the same goal of reducing total energy intake. Unfortunately, despite the presence of numerous dietary programs, few have been studied in a systematic manner. The most popular include low calorie (eg, Weight Watchers International, Inc); very low calorie; high protein and low carbohydrate (eg, Atkins Nutritionals, Inc); and low fat diets. Low calorie diet (LCD): In general, LCDs provide a deficit of 500 calories per day. The most rigorously studied and recognized commercial weight loss program in this category is the Weight Watchers program. There are two different diet programs offered by Weight Watchers, the first being the 'Flex Program', in which members keep a total daily tally of 'points' based on the number of calories consumed. Their goal is to maintain a total number of 'points' within a range determined by their current weight and weight loss goal. 
Weight Watchers also offers a 'Core Plan', in which participants are provided with recommended servings from each of the food groups and allowed to choose from a list of nutritious food. The program is a hypocaloric, balanced deficit diet in which clients prepare their own meals. The program also includes an activity plan, a cognitive/behavioural support plan, group sessions and weekly meetings. The hallmark of the program is that the group support is facilitated by an individual who has lost weight and maintained their weight loss using the Weight Watchers program.

Four randomized, controlled trials have been sponsored by Weight Watchers to evaluate the weight loss efficacy of the program (23-26). In the largest, a multicentre trial, 423 participants were randomly assigned to attend Weight Watchers meetings or to participate in a self-help intervention, including two visits with a dietician. The dropout rate of $27 \%$ was similar in both groups. The Weight Watchers group lost 5.3\% $(4.3 \mathrm{~kg})$ of their initial weight after one year and maintained a weight loss of $3.2 \%(2.9 \mathrm{~kg})$ after two years, versus $1.5 \%$ $(1.3 \mathrm{~kg})$ and $0 \%(0.2 \mathrm{~kg})$, respectively among those in the selfhelp group $(\mathrm{P}<0.001)$. Interestingly, participants in the Weight Watchers group who achieved the greatest weight loss were those who attended the most group sessions (26).

In a single-centre study, 48 obese breast cancer survivors were randomly assigned to one of four groups: standard care; weekly Weight Watchers meetings; individual counselling with a dietician; or weekly Weight Watchers meetings plus individualized dietary counselling. The dropout rate for all four groups was $19 \%$ after one year. The individuals in the standard care group gained $0.9 \mathrm{~kg}$, those in the Weight Watchers group lost $2.6 \mathrm{~kg}$, those who received individual counselling lost $8.0 \mathrm{~kg}(\mathrm{P}<0.05$ versus standard care $)$ and those attending both Weight Watchers and individual care lost $9.4 \mathrm{~kg} \quad(\mathrm{P}<0.05$ versus standard care) (24). Interestingly, Weight Watchers was not noted to be superior to individual care, thus emphasizing the importance of a supportive program that incorporates behavioural modification, rather than diet type alone.

Weight loss maintenance in overweight individuals was evaluated one to five years after their completion of the Weight Watchers program (27). Participants who had successfully completed the Weight Watchers program were contacted via a phone survey. Two hundred fifty-eight people were recruited and weighed. The percentage of weight loss regained at one to five years ranged between $30 \%$ and $80 \%$. At five years, $20 \%$ of individuals remained within five pounds of their goal weight, $40 \%$ maintained a weight loss of at least $5 \%$, and $20 \%$ maintained a weight loss of $10 \%$ or more. The percentage of participants who were still below their initial weight was $70 \%$. As such, the participants were successful in maintaining a weight loss that is thought to be sufficient to reduce obesity-related complications and morbidity (8), proving that the Weight Watchers program is an effective weight loss and maintenance program. Its success can likely be attributed to the supportive and individualized environment with likeminded individuals.

Very low calorie diet (VLCD): A VLCD is defined as a total daily calorie intake of less than or equal to $800 \mathrm{kcal} /$ day. The weight loss mechanism is secondary to severe calorie restriction. VLCDs are usually implemented by replacing a patient's regular food choices with specific foods or liquid diets. In one review, weight loss with VLCDs averaged $1.5 \mathrm{~kg}$ to $2.5 \mathrm{~kg}$ per week and a total loss of $20 \mathrm{~kg}$ after 12 to 16 weeks, compared with LCDs, which led to a weight loss of $0.4 \mathrm{~kg}$ to $0.5 \mathrm{~kg}$ per week and a total average weight loss of $6 \mathrm{~kg}$ to $8 \mathrm{~kg}$ (28).

Studies comparing short-term (four to six weeks) weight loss with VLCDs (energy restriction varied from $240 \mathrm{kcal}$ to $880 \mathrm{kcal})$ and LCDs ( $800 \mathrm{kcal} /$ day to $1200 \mathrm{kcal} /$ day $)$ show there was a trend toward greater weight loss in the VLCD groups than in the LCD groups, although this was not statistically significant (29).

Two randomized, controlled trials evaluated intermediate weight loss results after 24 to 26 weeks on a VLCD or LCD. Weight loss was similar between the two groups and no tendency to greater weight reduction with VLCDs was identified $(29,30)$

There are several randomized, controlled trials in which long-term weight loss maintenance of VLCDs was calculated using the amount of weight regained as the percentage of initial weight loss (from one to five years) (31-33). The two fiveyear follow-up studies revealed variable per cent weight regain, ranging between $121 \%$ and $45 \%(31,32)$. Although less weight regain was noted in patients who exercised and received behavioural therapy, this was not reproduced by all studies (31).

Overall, the role of VLCDs in weight loss maintenance is inconsistent $(9,34)$. VLCDs are not recommended beyond 16 weeks, after which point a LCD should be initiated. Although they are effective at achieving substantial initial weight loss, maintenance of weight loss over the long term is not satisfactory and weight regain when the diet is stopped is often rapid, indicating that a more sustainable approach rather than such extreme calorie restriction may afford better longterm success (28). Due to VLCDs resulting in rapid weight loss, they can be associated with a number of medical risks and patients should be medically supervised.

Low carbohydrate diet: Low carbohydrate diets are relatively high in fat and protein while restricting carbohydrate intake to $20 \mathrm{~g}$ per day (35). The Atkins diet, the most popular example, is a low carbohydrate, high protein and high fat diet. In the initial two-week induction phase, carbohydrate intake is limited to $20 \mathrm{~g} /$ day. Subsequently, in the maintenance phase, dieters are allowed to add $5 \mathrm{~g}$ of carbohydrates per week to approximately $50 \mathrm{~g}$ per day without any restriction to fat or protein intake. The principle behind this diet is that depletion of glycogen stores because of severe carbohydrate restriction leads to excretion of bound water, and the ketogenic nature of the diet suppresses appetite. The high protein content is highly satiating, reducing spontaneous food intake and thus decreasing energy intake (36).

In a one-year multicentre trial, 63 obese patients were randomly assigned to either the Atkins diet or a conventional diet, described as a low calorie, high carbohydrate and low fat diet $(1200 \mathrm{kcal} /$ day to $1500 \mathrm{kcal} /$ day for women and $1500 \mathrm{kcal} /$ day to $1800 \mathrm{kcal} /$ day for men, with $60 \%$ of calories from carbohydrate, $25 \%$ from fat and $15 \%$ from protein) (30). Individuals in both groups met with a registered dietician at three, six and 12 months to review dietary issues. Subjects on the Atkins diet achieved a significantly greater change in their mean body weight than subjects on the conventional diet at three months $(-6.8 \% \pm 5.0 \%$ versus $-2.7 \% \pm 3.7 \%$, respectively; $\mathrm{P}=0.001)$ and six months $(-7.0 \% \pm 6.5 \%$ versus $-3.2 \pm 5.6 \%$, respectively; $\mathrm{P}=0.02)$. However, at 12 months there was no significant difference between the two groups $(-4.4 \% \pm 6.7 \%$ versus 
$-2.5 \% \pm 6.3 \%$ of body weight, respectively; $\mathrm{P}=0.26)$. These results were duplicated in other studies, which demonstrated a better initial weight loss in the low carbohydrate diet $(37,38)$ but no difference between the diets after one year (38), suggesting that there is greater weight regain in the low carbohydrate group and that long-term adherence to such diets is difficult.

Low fat diet: A low fat diet is defined as one providing $0.7 \mathrm{kcal} / \mathrm{g} /$ day or less of fat calories. A meta-analysis compared low carbohydrate diets with no restriction to energy intake (maximum intake of $60 \mathrm{~g}$ of carbohydrates per day) to low fat diets (maximum allowance of $30 \%$ of daily energy intake from fat) in individuals with a BMI of at least $25 \mathrm{~kg} / \mathrm{m}^{2}$. Only intention-to-treat trials with a six-month follow-up period were analyzed. Five trials met these criteria. After six months, individuals who were randomly assigned to the low carbohydrate diets had lost more weight, with a mean difference in weight loss of $-3.3 \mathrm{~kg}$ ( $95 \%$ CI $-5.3 \mathrm{~kg}$ to $-1.4 \mathrm{~kg}$ ). The difference was not apparent at 12 months, with a mean difference in weight loss of $-1.0 \mathrm{~kg}$ (95\% CI $3.5 \mathrm{~kg}$ to $1.5 \mathrm{~kg})$. These results indicate that low carbohydrate diets are more effective for short-term weight loss than low fat diets but this response is not sustained for long-term weight maintenance (39).

Another study evaluated a lower fat diet incorporating higher carbohydrate intake, without focusing on weight loss and calorie reduction. In the Women's Health Initiative Dietary Modification Trial of 48,835 postmenopausal women (40), 40\% were randomly assigned to group and individual sessions to help reduce dietary fat intake (total fat intake of $20 \%$ per day) and increase ingestion of fruit, vegetables (five or more servings) and whole grains (six or more servings). The remainder of the women were assigned to receive a balanced diet without any contact with a dietician (control group). Women in the intervention group lost more weight (mean, $2.2 \mathrm{~kg}$ ) and maintained a lower weight at 7.5 years, but the difference was not significant. No tendency to gain weight in the intervention group was noted. The greatest weight loss was seen in women who had reduced their calories from fat.

However, low fat diets may be no more effective than other types of weight reduction diets, based on a meta-analysis of six trials evaluating the efficacy of low-fat dietary counselling for the purpose of weight loss (41). Overall, there are conflicting results on the effectiveness of low fat diets and thus, their efficacy remains unclear.

Diet compliance: Adherence is difficult for most participants on any diet. This was demonstrated in a single-centre trial of obese patients (mean BMI equal to $35 \mathrm{~kg} / \mathrm{m}^{2}$ ) with the metabolic syndrome who were randomly assigned to three diets: Atkins, Weight Watchers and very low fat (42). At one year, there was a trend toward a higher dropout rate in the low carbohydrate and very low fat diets, compared with other more moderate diets (Atkins, 48\%; very low fat, 50\%; and Weight Watchers, 35\%). The average weight loss was $4 \mathrm{~kg}$ to $7 \mathrm{~kg}$ in those who completed the study. In the intention-totreat analysis, the mean weight loss was similar for all three diets and ranged between only $2 \mathrm{~kg}$ and $3 \mathrm{~kg}$, but there was no statistically significant difference between diets $(\mathrm{P}<0.4)$. Despite weight loss in individuals who were able to adhere to the diet, no single diet resulted in a satisfactory adherence rate that did not decline over time $(\mathrm{P}<0.001)$. Interestingly, diet adherence was the most important predictor of weight loss and reduction of cardiovascular risk factors than the specific diet. Similar trends are noted in other studies, showing attrition rates after one year ranging between 31\% and $48 \%$ in the low carbohydrate diet group (36) and between $37 \%$ and $50 \%$ in those individuals randomly assigned to the low fat group (39).

Clinical benefits of diets: Essentially, the ultimate goal of weight loss is to improve clinical outcomes in obesity-related complications and disease morbidity. The effects of calorie restriction in humans have been examined. Participants were randomly assigned for six months to one of the following groups: control (weight maintenance diet), calorie restriction (25\% calorie restriction of baseline energy requirements), calorie restriction with exercise $(12.5 \%$ calorie restriction plus $12.5 \%$ increase in energy expenditure by structured exercise) or a VLCD ( $890 \mathrm{kcal} /$ day until $15 \%$ weight loss, followed by a weight maintenance diet). The weight change in these diets was $-1.0 \%,-10.4 \%,-10.0 \%$ and $-13.9 \%$, respectively. Two biomarkers of longevity, fasting insulin $(\mathrm{P}<0.01)$ and body temperature $(\mathrm{P}<0.05)$, were significantly reduced with prolonged calorie restriction (43). Relative improvements in insulin sensitivity and triglyceride levels were noted in patients assigned to the Atkins diet, even after adjustment for degree of weight loss (37).

A modest but statistically significant improvement in some cardiovascular risk factors was noted in patients on the Weight Watchers, Atkins and very low fat diets (42). Despite evidence of positive effects of weight loss on cardiovascular risk factors, evidence is lacking on their impact on cardiovascular outcomes, likely due to inadequate study follow-up.

The Weight Watchers diet, a comprehensive weight loss program, results in a mean weight loss of $5 \%$, which can be maintained by participants $(23,25)$. Interestingly, this amount of weight loss is sufficient to improve obesity-related complications $(9,44)$. Thus, even moderate weight loss has health benefits. Furthermore, it seems that no single type of diet is best suited for every individual. Given low compliance rates with any diet, certain dietary programs may be more suitable for some than for others. Different diets have different effects on cardiovascular risk factors and a patient's medical profile may guide choice of diet. The degree of metabolic syndrome may influence the degree of carbohydrate restriction. Potentially, dietary adherence may be improved by offering a variety of dietary options to patients and matching those with patient preference, lifestyle and cardiovascular profile to optimize weight loss and thus, medical benefits.

\section{Physical activity}

Obesity is related to a sedentary lifestyle. Exercise causes lipolysis, resulting in free fatty acid release from triglycerides stored in fat for use as an energy source by muscle, increasing energy expenditure (45). Although some reports indicate that exercise alone can produce a $2 \%$ to $3 \%$ reduction in $\mathrm{BMI}$, it is a more effective weight loss tool when used in conjunction with dietary modification. The majority of the literature suggests that physical activity alone is ineffective in achieving initial weight loss or results in only modest weight loss of a few kilograms (46). However, physical activity can help in long-term weight loss maintenance. Several series of observations have found that subjects who achieved successful long-term weight loss maintenance had participated in a regular exercise program (47). 
TABLE 1

\section{Behavioural therapy principles to assist with weight loss}

- Develop realistic goals with patients

- Design a weight loss plan targeting small, incremental diet and activity goals

- Motivate patients to self-monitor diet and physical activity

- Aid patients in identifying and solving problems that are weight loss barriers

- Arrange regular clinic follow-ups with either the gastroenterologist or other medical personnel to

- Record weight;

- Review food records;

- Provide continued encouragement and motivation; and

- Consider group behaviour therapy in patients who are unsuccessful

with weight loss with less aggressive methods

A starting program of $30 \mathrm{~min}$ to $45 \mathrm{~min}$ of moderate exercise (eg, brisk walking) at least three days per week is recommended. This amount of physical activity expends approximately $150 \mathrm{kcal} /$ day (500 to 1000 calories per week). For some, this may not be adequate energy expenditure and these individuals may require a loss of 2000 calories or more per week to ensure weight loss maintenance. Any form of physical activity is appropriate as long as it increases heart rate and energy expenditure. Walking is the most common, safe and accessible mode of exercise that is prescribed. The National Weight Control Registry recommends that individuals initially walk 4000 steps per day, with a gradual increase to 12,000 steps per day over a period of six months (45).

\section{Behavioural modification}

Behavioural strategies are designed to change patients' dietary and exercise habits. They target obstacles that limit adherence to diets. These strategies include self-monitoring of eating habits and physical activity, stress management of situations that lead to overeating, avoiding situations that lead to incidental eating, cognitive restructuring to correct unrealistic goals and misconceptions about weight loss and body image, social support from family and friends, and relapse prevention after episodes of overeating or weight gain.

The American Gastroenterological Association's guidelines suggest that gastroenterologists incorporate behavioural therapy principles to assist with weight loss (Table 1). Individuals who receive regular behavioural therapy such as regular contact with treatment providers are more likely to achieve and maintain long-term weight loss.

\section{Pharmacotherapy}

Although there are a wide variety of weight loss agents that have been tested in the treatment of obesity, currently only sibutramine and orlistat are approved in Canada. In addition to absolute weight loss, there are several important clinical benefits on lipids and blood sugar control achieved by these agents (Table 2). We will discuss the role of these agents in the induction and maintenance of weight loss, and briefly highlight future directions in pharmacotherapy with rimonabant (Table 3).

Antiobesity drug therapy is indicated for those individuals who cannot achieve weight loss despite an adequate trial of lifestyle modification. Pharmacotherapy should only be prescribed in conjunction with lifestyle modifications, and not as
TABLE 2

Clinical benefits of anti-obesity pharmacotherapy

\begin{tabular}{ll}
\hline Sibutramine & Orlistat \\
\hline$\cdot$ Improves HbA1C levels & $\cdot$ Improves HbA1C levels \\
- Improves blood glucose levels & $\cdot$ Improves blood glucose levels \\
- Delays diabetes & $\cdot$ Lowers lipid levels \\
& $\cdot$ Lowers total cholesterol levels \\
& $\cdot$ Lowers low-density lipoprotein levels
\end{tabular}

HbA1C Glycosylated hemoglobin

TABLE 3

Induction of weight loss with pharmacotherapy

\begin{tabular}{|c|c|c|c|c|c|}
\hline Drug & Reference & $\begin{array}{c}\text { Patients, } \\
n\end{array}$ & $\begin{array}{c}\text { Duration } \\
\text { of } \\
\text { therapy, } \\
\text { years }\end{array}$ & $\begin{array}{c}\text { Dose, } \\
\text { mg }\end{array}$ & $\begin{array}{c}\text { Weight } \\
\text { loss } \\
\text { outcome, } \\
\text { kg (P) }\end{array}$ \\
\hline Sibutramine & $\begin{array}{l}\text { Smith IG, } \\
\text { Goulder MA (47) }\end{array}$ & 485 & 1 & 15 od & $\begin{array}{c}6.4 \\
(<0.001)\end{array}$ \\
\hline Orlistat & $\begin{array}{l}\text { Davidson MH, } \\
\text { Hauptman J, } \\
\text { DiGirolamo M, } \\
\text { et al (57) }\end{array}$ & 880 & 1 & 120 tid & $\begin{array}{c}8.76 \\
(<0.001)\end{array}$ \\
\hline Rimonabant & $\begin{array}{l}\text { Pi-Sunyer FX, } \\
\text { Aronne LJ, } \\
\text { Heshmati HM, } \\
\text { et al (58) }\end{array}$ & 1602 & 1 & 20 od & $\begin{array}{c}6.3 \\
(<0.001)\end{array}$ \\
\hline
\end{tabular}

od Once daily; tid Three times per day

monotherapy for obesity. Patients with a BMI of $30 \mathrm{~kg} / \mathrm{m}^{2}$ or more, with no concomitant comorbid diseases and those with a BMI of $27.0 \mathrm{~kg} / \mathrm{m}^{2}$ to $29.9 \mathrm{~kg} / \mathrm{m}^{2}$ with two comorbid conditions (hypertension, dyslipidemia, coronary artery disease, type II diabetes or sleep apnea) may be candidates for pharmacological therapy.

Sibutramine: Sibutramine was initially developed as an antidepressant and was incidentally found to reduce body weight, decrease appetite and increase satiety. It inhibits norepinephrine and serotonin reuptake without stimulating their release (48). There have been more than 10 prospective randomized clinical trials to date. Three trials lasting at least one year demonstrated a weight loss of $4 \mathrm{~kg}$ or $5 \%$ more than placebo; $35 \%$ more patients achieved at least 5\% weight loss and $15 \%$ more patients achieved at least $10 \%$ weight loss than patients ingesting the placebo.

Patients who received $10 \mathrm{mg} /$ day or $15 \mathrm{mg} /$ day of sibutramine experienced a greater weight loss than those who received the placebo with dietary advice over a one-year period, with a weight reduction of $4.4 \mathrm{~kg}, 6.4 \mathrm{~kg}$ and $1.6 \mathrm{~kg}$ $(\mathrm{P} \leq 0.01)$, respectively $(49)$. The only side effect reported was dry mouth, which occurred more frequently in the treatment group. Withdrawal rates from the study because of lack of efficacy were higher in the placebo group $(21 \%)$ compared with the sibutramine group.

Sibutramine has also been shown to be effective at weight loss maintenance (50). In one study, obese patients who lost at least $6 \mathrm{~kg}$ during four weeks of a VLCD were randomly assigned to either sibutramine $10 \mathrm{mg} /$ day or placebo for one year. The treatment group had a mean weight loss of $5.2 \mathrm{~kg}$, compared with the placebo group weight loss of only 
TABLE 4

Guide for selecting obesity treatment

\begin{tabular}{lccccc}
\hline & \multicolumn{5}{c}{ Body mass index category, $\mathrm{kg} / \mathrm{m}^{2}$} \\
\cline { 2 - 6 } Treatment & $\mathbf{2 5 - 2 6 . 9}$ & $\mathbf{2 7 - 2 9 . 9}$ & $\mathbf{3 0 - 3 4 . 9}$ & $\mathbf{3 5 - 3 9 . 9}$ & $\geq \mathbf{4 0}$ \\
\hline $\begin{array}{c}\text { Diet, exercise and } \\
\text { behaviour }\end{array}$ & + & + & + & + & + \\
$\begin{array}{l}\text { Pharmacotherapy } \\
\text { Surgery }\end{array}$ & - & $\begin{array}{c}\text { With co- } \\
\text { morbidities }\end{array}$ & + & + & + \\
& - & - & - & $\begin{array}{c}\text { With co- } \\
\text { morbidities }\end{array}$ & + \\
\hline
\end{tabular}

Reproduced/adapted with permission from reference 9

$0.5 \mathrm{~kg}(\mathrm{P}=0.004)$. Seventy-five per cent of patients in the sibutramine group maintained their weight loss after the VLCD ended, compared with $42 \%$ in the placebo group $(\mathrm{P}<0.01)(50)$.

The main side effects of sibutramine are cardiovascular problems (tachycardia and increase in blood pressure), nervousness and insomnia. Some patients may also complain of dry mouth and constipation. The drug is contraindicated in patients using monoamine oxidase inhibitors and selective serotonin reuptake inhibitors.

Orlistat: Orlistat is a potent, irreversible inhibitor of gastric and pancreatic lipases that reduces systemic absorption of dietary fat by $30 \%$.

Eleven prospective, randomized clinical trials have evaluated the efficacy of orlistat. Overall, the findings reveal a $3 \mathrm{~kg}$ weight loss or $3 \%$ greater reduction in weight than with the ingestion of a placebo. It also reduced low density lipoprotein and cholesterol levels independently of body weight reduction, delayed diabetes, improved glycemic control in diabetic patients, and significantly reduced systolic and diastolic blood pressure. However, no studies have demonstrated mortality advantage or reduction in cardiovascular diseases.

Orlistat has been evaluated in weight loss maintenance. At one year, patients treated with $120 \mathrm{mg}$ of orlistat, three times per day had significantly less weight regain than those in the placebo group (33\% versus 59\%; $\mathrm{P}<0.001$ ) (51).

Side effects include liquid stools, steatorrhea, fecal urgency, incontinence, flatulence, abdominal cramping and fat-soluble vitamin deficiencies.

Rimonabant: Rimonabant, a cannabinoid receptor antagonist, has been investigated as a treatment option for both smoking cessation and obesity. Endogenous cannabinoid receptor agonists are present in the brain. Central nervous system levels of cannabinoid receptors increase with greater demand of food. The cannabinoid-1 receptor plays a role in the regulation of appetite.

Trials have evaluated the efficacy of rimonabant as a weight loss agent $(52,53)$. In one trial, 1507 patients with a BMI of more than $30 \mathrm{~kg} / \mathrm{m}^{2}$ (with treated or untreated dyslipidemia, hypertension or both) were randomly assigned to receive rimonabant $(5 \mathrm{mg} /$ day or $20 \mathrm{mg} /$ day $)$ or placebo, in addition to a hypocaloric diet (600 kcal/day deficit) (52). The mean dose-dependant weight loss at one year was $-3.4 \mathrm{~kg} \pm 5.7 \mathrm{~kg},-6.6 \mathrm{~kg} \pm 7.2 \mathrm{~kg}$ and $-1.8 \mathrm{~kg} \pm 6.4 \mathrm{~kg}$ in the rimonabant $5 \mathrm{mg}, 20 \mathrm{mg}$ and placebo groups, respectively. Rimonabant $20 \mathrm{mg}$ resulted in significantly greater improvements than the placebo in waist circumference, high density lipoproteins, triglycerides, insulin resistance and the metabolic syndrome. Side effects, including mood changes, nausea and vomiting, diarrhea, headache, dizziness and anxiety were more frequent in the rimonabant $20 \mathrm{mg}$ group than in the $5 \mathrm{mg}$ or placebo groups.

\section{Endoscopy}

Endoscopically placed gastric balloons have limited availability in Canada. A soft, saline-filled balloon is placed intragastrically, and induces satiety and restriction. The weight results with this intervention appeared to be transient and inconsistent (54). Placement can be complicated by nausea, vomiting, abdominal pain, gastric erosions, ulcers, balloon deflation and balloon migration, resulting in bowel obstruction. Usually, balloons need to be removed and replaced every three to six months to prevent complications. If they are placed for longer periods, appropriate monitoring with imaging is required.

\section{Surgical}

Weight loss surgeries are reserved for patients with severe obesity. Eligible patients are those with a BMI of $40 \mathrm{~kg} / \mathrm{m}^{2}$ or more in whom diet and medical therapy have failed or patients with a BMI of $35 \mathrm{~kg} / \mathrm{m}^{2}$ or more with comorbid conditions. Surgical weight loss can be achieved by restrictive, malabsorptive or combination procedures.

Roux-en-Y gastric bypass surgery results in weight loss by gastric restriction, causing early satiety and malabsorption, as well as reduction in hunger due to a decrease in ghrelin levels and increased PYY. The approximate weight loss at one year is $50 \%$ (55). Complications associated with this surgery include deficiencies in iron, calcium, vitamin $B_{12}$, fat-soluble vitamins, folic acid and electrolytes.

Vertical banded gastroplasty is a purely restrictive procedure by which the patient is left with a pouch that dilates to only $250 \mathrm{~mm}$ in diameter. Vomiting is a common side effect. Weight loss with compliance is $60 \%$ (56). Drawbacks of the procedure are that high calorie beverage ingestion can eventually lead to weight gain. Furthermore, the pouch can expand with overeating.

Laparoscopic adjustable gastric banding, another purely restrictive procedure, involves placing a small silicone band around the fundus of the stomach. It is a short day-surgery and can be adjusted after placement. Weight loss seen after this procedure is also approximately $60 \%(56)$.

\section{CONCLUSIONS}

A thorough medical assessment is required to identify patients who are obese or at risk for obesity or obesity-related complications. The medical evaluation should entail a complete history (eating patterns, behavioural patterns, physical activity, weight history, attempts at weight loss, and obesity-related risk factors and complications) and physical examination (including a BMI and waist circumference measurement), as well as appropriate laboratory and diagnostic testing (37).

Several antiobesity treatment options in isolation or in combination are available to physicians. Selecting appropriate obesity therapy can be guided by BMI and obesity-related complications (Table 4) $(9,10)$. The available therapeutic armamentarium ranges from nonpharmacological therapy, such as cognitive and behavioural treatment, physical activity and diets; pharmacotherapy to endoscopic and surgical procedures. 


\section{REFERENCES}

1. Statistics Canada. Canadian Community Health Survey, 2004.

2. Young LR, Nestle M. The contribution of expanding portion sizes to the US obesity epidemic. Am J Public Health 2002;92:246-9.

3. Birmingham CL, Muller JL, Palepu A, Spinelli JJ, Anis AH. The cost of obesity in Canada. CMAJ 1999;160:483-8.

4. Clark JM, Brancati FL, Diehl AM. Nonalcoholic fatty liver disease. Gastroenterology 2002;122:1649-57.

5. Hubscher SG. Role of liver biopsy in the assessment of non-alcoholic fatty liver disease. Eur J Gastroenterol Hepatol 2004;16:1107-15.

6. Adams LA, Lymp JF, St Sauver J, et al. The natural history of nonalcoholic fatty liver disease: A population-based cohort study. Gastroenterology 2005;129:113-21.

7. Adams LA, Angulo P. Treatment of non-alcoholic fatty liver disease. Postgrad Med J 2006;82:315-22.

8. Clinical guidelines on the identification, evaluation, and treatment of overweight and obesity in adults - the evidence report. National Institutes of Health. Obes Res 1998;6(Suppl 2):51S-209S. (Erratum in 1998;6:461-2)

9. National Heart, Lung and Blood Institute, North American Association for the Study of Obesity. Practical Guide to the Identification, Evaluation, and Treatment of Overweight and Obesity in Adults (Publication number 00-4084). National Institute of Health, 2000.

10. Serdula MK, Mokdad AH, Williamson DF, Galuska DA, Mendlein JM, Heath GW. Prevalence of attempting weight loss and strategies for controlling weight. JAMA 1999;282:1353-8.

11. Perri MG. The maintenance of treatment effects in the long-term management of obesity. Clin Psychol Sci Pract 1998;5:526-43.

12. Blackburn G. Effect of degree of weight loss on health benefits. Obes Res 1995;3(Suppl 2):211S-6S.

13. Clement K, Vaisse C, Manning BS, et al. Genetic variation in the beta 3-adrenergic receptor and an increased capacity to gain weight in patients with morbid obesity. N Engl J Med 1995;333:352-4.

14. Ristow M, Muller-Wieland D, Pfeiffer A, Krone W, Kahn CR. Obesity associated with a mutation in a genetic regulator of adipocyte differentiation. N Engl J Med 1998;339:953-9.

15. Tschop M, Weyer C, Tataranni PA, Devanarayan V, Ravussin E, Heiman ML. Circulating ghrelin levels are decreased in human obesity. Diabetes 2001;50:707-9.

16. Wren AM, Seal LJ, Cohen MA, et al. Ghrelin enhances appetite and increases food intake in humans. J Clin Endocrinol Metab 2001;86:5992.

17. Degen L, Oesch S, Casanova M, et al. Effect of peptide YY3-36 on food intake in humans. Gastroenterology 2005;129:1430-6.

18. Cohen MA, Ellis SM, Le Roux CW, et al. Oxyntomodulin suppresses appetite and reduces food intake in humans. J Clin Endocrinol Metab 2003;88:4696-701.

19. Flint A, Raben A, Astrup A, Holst JJ. Glucagon-like peptide 1 promotes satiety and suppresses energy intake in humans. J Clin Invest 1998; 101:515-20.

20. Mizuno TM, Kelley KA, Pasinetti GM, Roberts JL, Mobbs CV. Transgenic neuronal expression of proopiomelanocortin attenuates hyperphagic response to fasting and reverses metabolic impairments in leptin-deficient obese mice. Diabetes 2003;52:2675-83.

21. Matsuzawa Y, Funahashi T, Kihara S, Shimomura I. Adiponectin and metabolic syndrome. Arterioscler Thromb Vasc Biol 2004;24:29-33.

22. Oh DK, Ciaraldi T, Henry RR. Adiponectin in health and disease. Diabetes Obes Metab 2007;9:282-9.

23. Heshka S, Greenway F, Anderson JW, et al. Self-help weight loss versus a structured commercial program after 26 weeks: A randomized controlled study. Am J Med 2000;109:282-7.

24. Djuric Z, DiLaura NM, Jenkins I, et al. Combining weight-loss counseling with the Weight Watchers plan for obese breast cancer survivors. Obes Res 2002;10:657-65.

25. Rippe JM, Price JM, Hess SA, et al. Improved psychological well-being, quality of life, and health practices in moderately overweight women participating in a 12 -week structured weight loss program. Obes Res 1998;6:208-18.

26. Heshka S, Anderson JW, Atkinson RL, et al. Weight loss with self-help compared with a structured commercial program: A randomized trial. JAMA 2003;289:1792-8.

27. Lowe MR, Miller-Kovach K, Phelan S. Weight-loss maintenance in overweight individuals one to five years following successful completion of a commercial weight loss program. Int J Obes Relat Metab Disord 2001;25:325-31.
28. Very low-calorie diets. National Task Force on the Prevention and Treatment of Obesity, National Institutes of Health. JAMA 1993;270:967-74.

29. Rossner S, Flaten H. VLCD versus LCD in long-term treatment of obesity. Int J Obes Relat Metab Disord 1997;21:22-6.

30. Foster GD, Wyatt HR, Hill Jo, et al. A randomized trial of a low-carbohydrate diet for obesity. N Engl J Med 2003;348:2082-90.

31. Wadden TA, Sternberg JA, Letizia KA, Stunkard AJ, Foster GD. Treatment of obesity by very low calorie diet, behavior therapy, and their combination: A five-year perspective. Int J Obes 1989;13(Suppl 2):39-46.

32. Torgerson JS, Agren L, Sjostrom L. Effects on body weight of strict or liberal adherence to an initial period of VLCD treatment. A randomised, one-year clinical trial of obese subjects. Int J Obes Relat Metab Disord 1999;23:190-7.

33. Ayyad C, Andersen T. Long-term efficacy of dietary treatment of obesity: A systematic review of studies published between 1931 and 1999. Obes Rev 2000;1:113-9.

34. Saris WH. Very-low-calorie diets and sustained weight loss. Obes Res 2001;9(Suppl 4):295S-301S.

35. Atkins RC. Dr. Atkins' New Diet Revolution. New York: Harper, 1992

36. Astrup A, Breum L, Toubro S, Hein P, Quaade F. The effect and safety of an ephedrine/caffeine compound compared to ephedrine, caffeine and placebo in obese subjects on an energy restricted diet. A double blind trial. Int J Obes Relat Metab Disord 1992;16:269-77.

37. Samaha FF, Iqbal N, Seshadri P, et al. A low-carbohydrate as compared with a low-fat diet in severe obesity. N Engl J Med 2003;348:2074-81.

38. Stern L, Iqbal N, Seshadri P, et al. The effects of low-carbohydrate versus conventional weight loss diets in severely obese adults: One-year follow-up of a randomized trial. Ann Intern Med 2004;140:778-85.

39. Nordmann AJ, Nordmann A, Briel M, et al. Effects of lowcarbohydrate vs low-fat diets on weight loss and cardiovascular risk factors: A meta-analysis of randomized controlled trials. Arch Intern Med 2006;166:285-93. (Erratum in 2006;166:932).

40. Howard BV, Manson JE, Stefanick ML, et al. Low-fat dietary pattern and weight change over 7 years: The Women's Health Initiative Dietary Modification Trial. JAMA 2006;295:39-49.

41. Pirozzo S, Summerbell C, Cameron C, Glasziou P. Advice on low-fat diets for obesity. Cochrane Database Syst Rev 2002:CD003640.

42. Dansinger ML, Gleason JA, Griffith JL, Selker HP, Schaefer EJ. Comparison of the Atkins, Ornish, Weight Watchers, and Zone diets for weight loss and heart disease risk reduction: A randomized trial. JAMA 2005;293:43-53.

43. Heilbronn LK, de Jonge L, Frisard MI, et al. Effect of 6-month calorie restriction on biomarkers of longevity, metabolic adaptation, and oxidative stress in overweight individuals: A randomized controlled trial. JAMA 2006;295:1539-48. (Erratum in 2006;295:2482).

44. Knowler WC, Barrett-Connor E, Fowler SE, et al, for the Diabetes Prevention Program Research Group. Reduction in the incidence of type 2 diabetes with lifestyle intervention or metformin. N Engl J Med 2002;346:393-403.

45. Fujioka K, Seaton TB, Rowe E, et al, for the Sibutramine/Diabetes Clinical Study Group. Weight loss with sibutramine improves glycaemic control and other metabolic parameters in obese patients with type 2 diabetes mellitus. Diabetes Obes Metab 2000;2:175-87.

46. Garrow JS, Summerbell CD. Meta-analysis: Effect of exercise, with or without dieting, on the body composition of overweight subjects. Eur J Clin Nutr 1995;49:1-10.

47. Klem ML, Wing RR, McGuire MT, Seagle HM, Hill JO. A descriptive study of individuals successful at long-term maintenance of substantial weight loss. Am J Clin Nutr 1997;66:239-46.

48. Luque CA, Rey JA. Sibutramine: A serotonin-norepinephrine reuptake-inhibitor for the treatment of obesity. Ann Pharmacother 1999;33:968-78.

49. Smith IG, Goulder MA, for the Subutramine Clinical Study 1047 Team. Randomized placebo-controlled trial of long-term treatment with sibutramine in mild to moderate obesity. J Fam Pract 2001;50:505-12.

50. Apfelbaum M, Vague P, Ziegler O, Hanotin C, Thomas F, Leutenegger E. Long-term maintenance of weight loss after a very-low-calorie diet: A randomized blinded trial of the efficacy and tolerability of sibutramine. Am J Med 1999;106:179-84. 
51. Hill JO, Hauptman J, Anderson JW, et al. Orlistat, a lipase inhibitor, for weight maintenance after conventional dieting: A 1-y study. Am J Clin Nutr 1999;69:1108-16.

52. Van Gaal LF, Rissanen AM, Scheen AJ, Ziegler O, Rossner S, for the RIO-Europe Study Group. Effects of the cannabinoid-1 receptor blocker rimonabant on weight reduction and cardiovascular risk factors in overweight patients: 1-year experience from RIO-Europe study. Lancet 2005;365:1389-97. (Erratum in 2005;366:370).

53. Despres JP, Golay A. Sjostrom L, for the Rimbonant in ObesityLipids Study Group. Effects of rimonabant on metabolic risk factors in overweight patients with dyslipidemia. N Engl J Med 2005;353:2121-34

54. Mathus-Vliegen EM, Tytgat GN. Intragastric balloon for treatmentresistant obesity: Safety, tolerance, and efficacy of 1-year balloon treatment followed by a 1-year balloon-free follow-up. Gastrointest Endosc 2005;61:19-27.
55. Korner J, Inabnet W, Conwell IM, et al. Differential effects of gastric bypass and banding on circulating gut hormone and leptin levels. Obesity (Silver Spring) 2006;14:1553-61.

56. Miller K, Pump A, Hell E. Vertical banded gastroplasty versus adjustable gastric banding: Prospective long-term follow-up study. Surg Obes Relat Dis 2007;3:84-90.

57. Davidson $\mathrm{MH}$, Hauptman J, DiGirolamo M, et al. Weight control and risk factor reduction in obese subjects treated for 2 years with orlistat: A randomized controlled trial. JAMA 1999;281:235-42. (Erratum in 1999;281:1174).

58. Pi-Sunyer FX, Aronne LJ, Heshmati HM, Devin J, Rosenstock J, for the RIO-North America Study Group. Effect of rimonabant, a cannabinoid-1 receptor blocker, on weight and cardiometabolic risk factors in overweight or obese patients: RIO-North America: A randomized controlled trial. JAMA 2006;295:761-75. (Erratum in 2006;295:1252). 


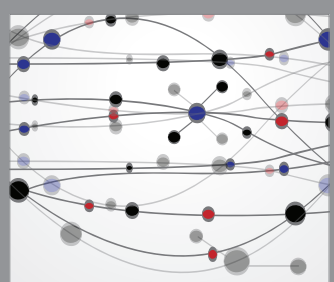

The Scientific World Journal
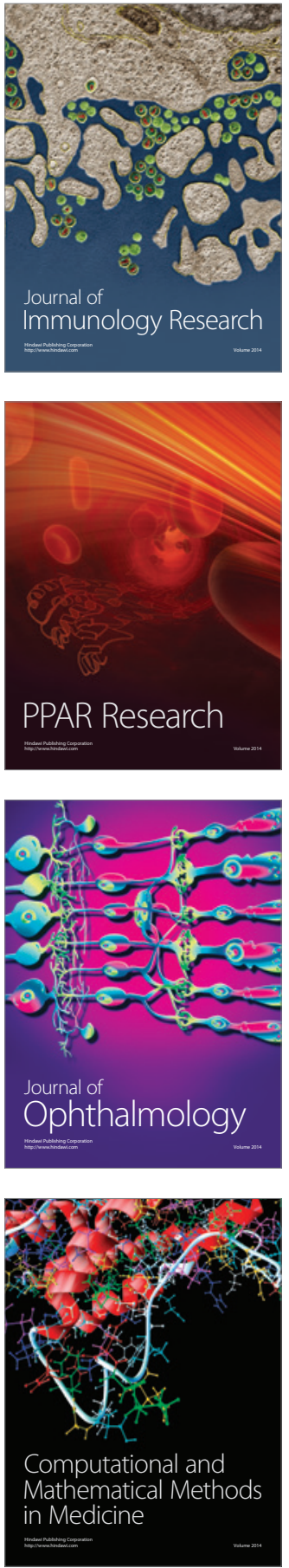

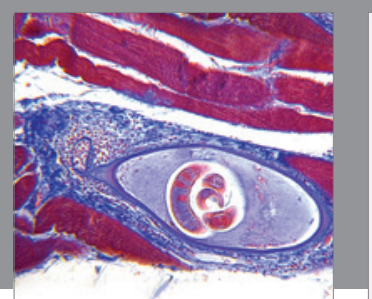

Gastroenterology Research and Practice

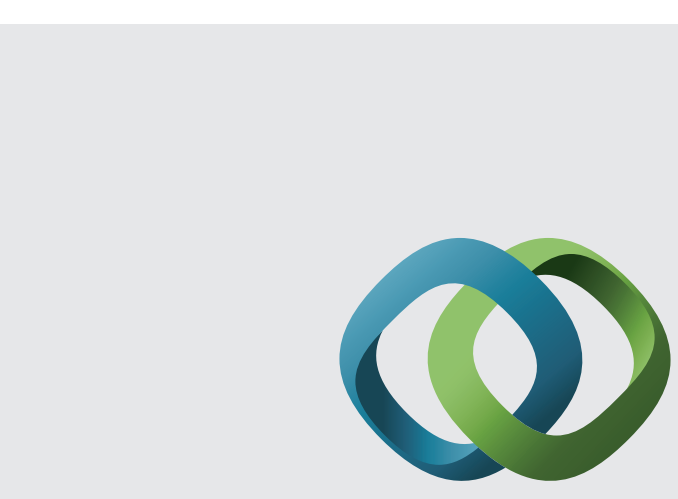

\section{Hindawi}

Submit your manuscripts at

http://www.hindawi.com
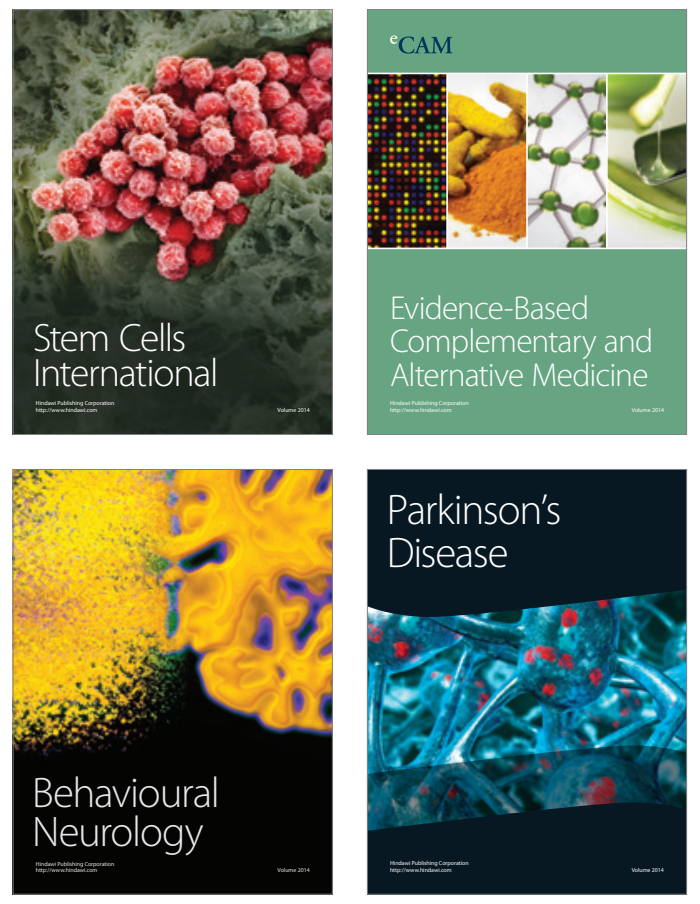
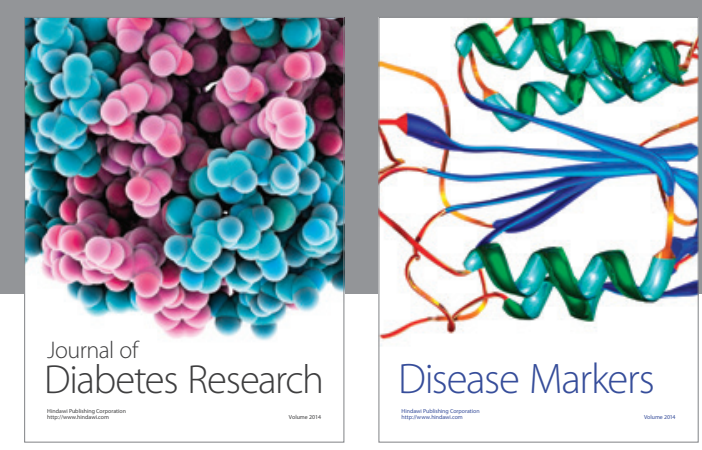

Disease Markers
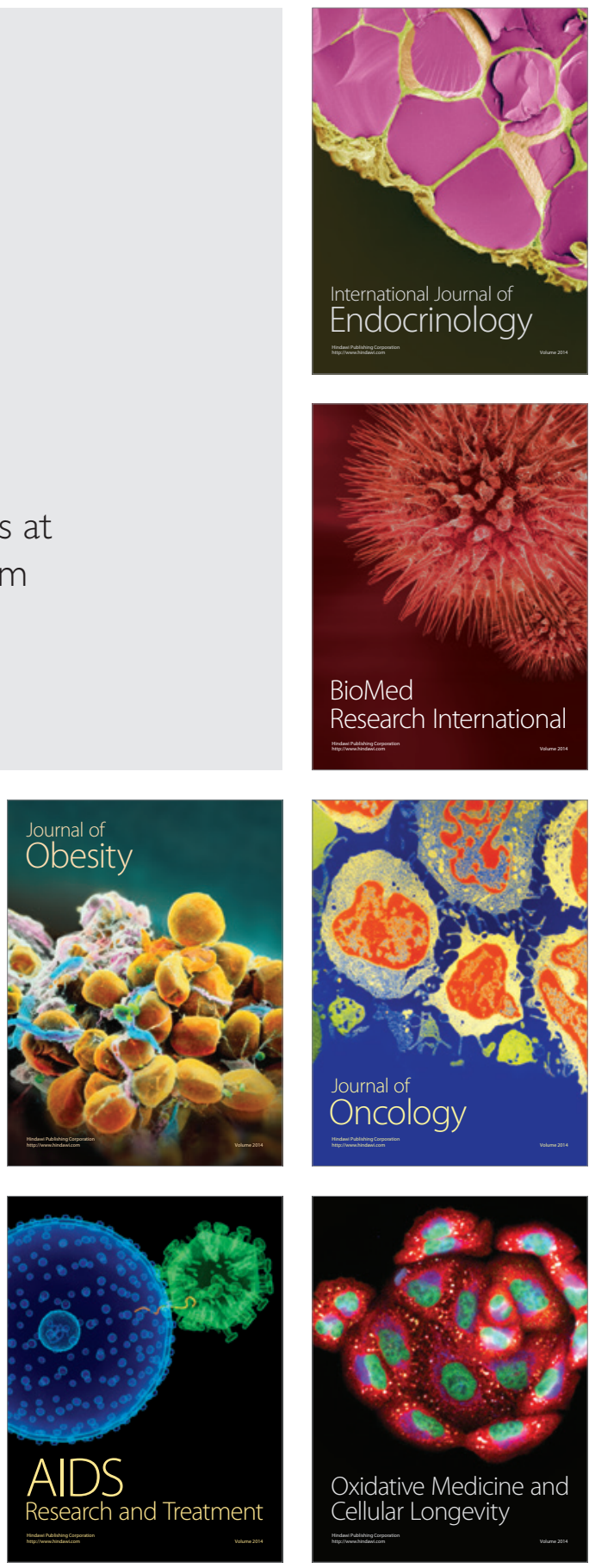